\title{
UNCERTAINTY AVOIDANCE, RISK AVOIDANCE AND PERCEIVED RISK: A CULTURAL PERSPECTIVE OF INDIVIDUAL INVESTORS
}

\author{
Imran Arshad, Yusnidah Ibrahim \\ School of Economics, Finance and Banking, Universiti Utara Malaysia, Malaysia
}

\begin{abstract}
Risk serves as an important aspect that can change the decision making of individuals, especially if it is related to investment decision making. The effects of risk on investment decision making have been extensively discussed in the literature but little of it assessed the dominance of various risk-related factors in investment decision making by individuals. In order to make up for this lack, this research studies the impact of risk avoidance, uncertainty avoidance and perceived risk on the investment intentions of individual investors in Pakistan and relate it to Hofstede's cultural dimension. The data was collected from individual investors and after screening, a sample of 548 was found useable for further analysis. Using SEM-PLS, it was found that risk avoidance and uncertainty avoidance significantly influence the investment intention of individual investors. On the other hand perceived risk does not influence the investment intentions of individual investors. In the evaluation of dominating factors, it was found that risk avoidance is the most significant and the strongest factor that influences the individual investors' investment intentions. This paper suggests that investment managers should work on strategies to change the risk avoidance behaviour of investors. Moreover, findings suggest that the cultural aspect is more important, and the level of risk avoidance should be kept in mind while offering stocks in the market. The Security Exchange Commission of Pakistan can prepare risk-adjusted products to enhance the level of intentions among the individual investors in Pakistan.
\end{abstract}

Keywords: Risk avoidance, Uncertainty avoidance, Perceived risk, Investment intentions 


\section{INTRODUCTION}

What prompts investors to choose one investment option over another? The standard behavioural answer is that investors are striving to minimize investment risk. This notion is based on Kahneman and Tversky's (1979) prospect theory, which states that people tend to be more risk-averse than risk-seeking when it comes to gains and investment decisions(Sevdalis, \& Harvey, 2007). Understanding individual decision making and designing tools to improve the decision making process remain a major concern of previous research that aim to provide individual welfare and raise public policy implications (Ferecatu \& Önçüler, 2016). In investment decision making the most common components considered by an investor are risk and uncertainty. Traditional microeconomic models of preferences tend to neglect behavioural influences on financial decisions or to discard them as noise. Risk and uncertainty are not only mathematical and statistical concepts but also psychological constructs (Wang, Keller, \& Siegrist, 2011). MacGregor, Slovic, Berry and Evensky (1999) elaborated that some financial advisors and planners defined risk similar to the traditional finance theory and include emotional and contextual factors for specific investment decisions only. But researchers in the emerging field of behavioural finance have started to investigate such influences. In fact, a body of empirical evidence now attests to the systematic impact of behavioural variables on financial decisions. Such variables include investor gender (e.g., Felton, Gibson, \& Sanbonmatsu, 2003; Olsen \& Cox, 2001), personality (e.g., Felton et al. 2003), and cultural profile (e.g., O'Barr \& Conley, 2000). A review of current literature shows that there are less focused studies which consider a variety of risks and their impact on investment decision making.

There has been an increased interest by researchers in assessing the influence of culture on consumer behaviour (De Mooij \& Hofstede, 2011). Culture is the homogeneity of characteristics of norms, values and institutions that distinguish human groups from each other (Eisingerich \& Rubera, 2010). Culture onlyexists by comparison based on several dimensions. There are five dimensions to assess cross-cultural differences among human groups. The most used cultural dimensions have been given by Hofstede (2001) which includes uncertainty avoidance, individualism/collectivism, power-distance, masculinity/femininity and long-term orientation. In the context of investment intentions, the current research uses uncertainty avoidance as one of the cultural dimensions that differentiates individual investors. According to Hofstede (2001), "uncertainty avoidance is the extent to which people feel threatened by unknown or ambiguous situations". In making cultural comparison of individual investors in Pakistan with those of other countries, it has been found that Pakistan scores (70) as compared to China (30), Malaysia (36) and India (40). The high score on uncertainty avoidance shows salient cultural difference between Pakistani investors and investors in China, Malaysia and India in terms of uncertainty avoidance in relation to individual investors' intention to invest in the stock market.

According to Hofstede and Hofstede (2001), avoidance of uncertainties and risks occurs when people are not comfortable due to doubt, ambiguity and insecurity. While there are various ways in which uncertainties and risks are avoided, people who are prone to avoid uncertainties and risks are more inclined to look for ways to minimise 
uncertainties (Lim, 2013). Additionally, researchers have also found that perceived risk affects people's risk attitudes, which in turn determines their behavioural intentions toward that risk (Brewer, Chapman, Gibbons, Gerrard, McCaul, \& Weinstein, 2007; Carvalho, Block, Sivaramakrishnan, Manchanda, \& Mitakakis, 2008; Pennings, Wansink, \& Meulenberg, 2002). Perceptions of selfrisk and behavioural intentions for the culturally similar condition significantly increased when the likelihood of threat occurrence was raised from low to high risk (Carvalho et al. 2008). Morse (1998) revealed that due to the difficulty in comparing risk exposure with the desired level of investments, it is difficult for investors to perceive the actual risk associated with the choice of specific investments that they encounter. A significant relationship between investors' investment decision and investors' self-assessed risk was found in previous studies (Bailey \& Kinerson, 2005; Hallahan, Faff, \& McKenzie, 2004). Dai, Forsythe, and Kwon (2014) argued that increased risk decreases the value of purchase intention. This, therefore, demonstrates that perceived risk has a negative relationship with purchase intentions.

In the investment context, Lim (2013) asserted that risk avoidance includes the avoidance from a particular threat situation which can be achieved by eliminating potential source of threat or avoiding the option which contains high exposure to risk. Individuals might choose a riskier option over a less risky option because they have a positive attitude towards risk. It is widely believed that higher the level of risk aversion the lower the investment intention of individual investors (Mayfield, Perdue, \& Wooten, 2008). Moreover, Enron (2010) explained that risk in investment options may reduce the inclination to invest by individuals. This is especially so when the investor senses a need for risk avoidance while investing with low capital return.

In reviewing the literature, it became obvious that there has been very little attention given by researchers to the cultural aspect of risk in investment and perceived risk of individual investors. The current study thus aims to investigate how uncertainty avoidance of individual investors, their perceived risk and risk avoidance can influence their intentions to invest in stocks

\section{Uncertainty avoidance and Investment Intentions}

Hofstede (2001) defined uncertainty avoidance as the extent to which individuals feel threatened by some unknown of an uncertain situation. In cross-cultural psychology, Hofstede and Hofstede (2001) explained that uncertainty avoidance is society's tolerance for uncertainty and ambiguity which depicts to what extent the members of a society handle the uneasy situation by minimising the level of uncertainty. It has been found investors' first preference is to avoid uncertainty while making investment decisions and uncertainty avoidance has a significant impact on investment decisions (Amirhosseini \& Okere, 2012)

Uncertainty avoidance is considered as a tendency to be uncomfortable with uncertain outcomes and that such situations are tolerated to a greater or lesser extent in different cultures. This was clearly highlighted in Becker and Flanegin's (2010) study, in which they examined students in the United States and Australia, and their findings indicate that Australian students had greater uncertainty avoidance than American students, implying that they were less capable of accepting change. Hofstede, Hofstede and Minkov (2010) presented how different countries scored on an uncertainty avoidance index. Pakistan 
scored (70), which is high on uncertainty avoidance as compared to China (40), India (40), Malaysia (36) and Singapore (80. This distinct cultural difference has also been shown to affect individuals' investment patterns. This may explain the low investment intentions among Pakistani investors as shown in figure 1.

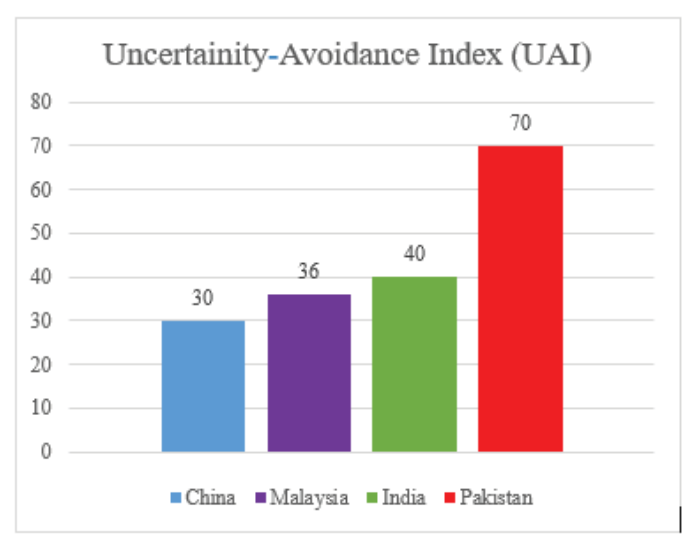

Figure 1. Uncertainty avoidance Index (UAI)

Previous studies such as Lim (2013) have examined the behaviours exhibited by individual investors based on their level of uncertainty avoidance and the difference between people with high and low uncertainty avoidance in financial decision making. Drakos (2006) reported negative impact of uncertainty on investment. Iyke and Ho (2017) stated that uncertainty may cause investors to invest more or less depending on their preference towards risk. In the present study, uncertainty avoidance is likely to influence investors' perception of uncertainty in investing in the stock market. Uncertainty avoidance attitude is expected to have a significant impact on investment intentions of individual investors. Based on the above discussion on uncertainty avoidance, it can be ascertained that uncertainty avoidance has a significant influence on investor intention to invest in stocks.

H1: Uncertainty avoidance will have a significant impact on investment intentions of individual investors.

\section{Risk avoidance and Investment Intentions}

Weber and Bottom (1989) defined risk avoidance as a tendency to be attracted or repelled by alternatives that are perceived as being riskier. Hofstede and Hofstede (2001) have suggested people who are more risk averse are more inclined to feel threatened by risky and ambiguous situations. Howcroft, Hewer and Hamilton (2003) said that investors when having high-risk perception tend to estimate the financial loss they may incur as a result of their decisions and they usually tend to develop strategies to reduce their risk (i.e. sourcing information) and make more riskadjusted decisions.

Hallahan, Faff and McKenzie (2004) also argued that people assess their risk tolerance level and try to reduce their exposure to unacceptable situations, leading to some form of risk management, which can be defined as a set of actions taken to change the risk arising from an investment. Knoll (2010) elaborated that investors need some indication as to whether the returns on an investment will meet their minimum requirements. For a given level of risk, investors seek to maximise their return. Risk is a factor that shapes people's decisions, such as when making an investment choice. Bennet, Selvam, Indhumathi, Ramkumar and Karpagam (2011) are of the view that when individuals perceive high probability of loss, they focused on risk-avoiding decisions and favoured interest-bearing accounts rather than investment in stocks.

Agreeing with Bennet et al. (2011), Quintal, Lee and Soutar (2010) expressed that when a purchase is perceived to have the risk of financial loss, the individual's behaviour towards the purchase of that particular product would be affected. 
This negative perception then influences the individual's behaviour towards that particular purchase. Rizvi and Ali (2011) discovered that Pakistani investors are more reluctant and unwilling to take risks. When faced with risks, Pakistani investors to some extent, tend to take the easy way out. They retracted their investments and avoided making any more investments.

Enron (2010) explained that risk in investment options may reduce the tendency to invest by individuals. Especially, the investor feels the need for risk avoidance while investing with low capital return. Risk avoidance usually involves the avoidance of a particular threat, which can be achieved by eliminating the source of risk or by avoiding alternatives that have exposure to that risk (Lim, 2013). While investing in stocks, individual investors perceive a higher level of risk and greater probability of loss. Therefore, the individual tends to make a risk-avoiding decision while investing their savings; in fact, they opt for interest-bearing accounts and not for investment (Gambetti \& Giusberti, 2012). Previous literature suggested that risk avoidance is directly related to the behavioural intentions of investors' personal finance decisions. It is generally argued that a risk avoidance attitude of investor would also refrain him/her from risky behaviour (Franklin \& Corter, 2010). In perspective insurance purchase, Bommier and Le Grand (2014) found that demand to purchase annuities decrease with increase in the risk avoidance behaviour. Bommier, Chassagnon and Le Grand (2012) clarified that there is a strong link between risk aversion and prudence, showing that precautionary savings increase with risk aversion, which in turn means that risk avoidance behaviour will decrease the investment. Based on the above discussion, the following hypothesis is postulated.
H2: Risk avoidance will significantly impact on the investment intentions of individual investors.

\section{Perceived Risk and Investment Intentions}

According to Dowling and Staelin (1994), perceived risk refers to the possibility that consumers perceive uncertainty or unfavourable consequences when deciding to purchase products or services. Behavioural intention is a popular topic in marketing and an important predictor of consumer behaviour. Siau and Shen (2003) pointed out that consumers have many doubts in perceiving transactions, signalling an increase in perceived risks leading to a decline in behavioural intention.

Aqueveque (2006) said that perceived risks developed by consumers through recognition of the purchase process would negatively influence behavioural intention. González Mieres, María Díaz Martín and Trespalacios Gutiérrez (2006) associated the perceived risk with important consequences related to health, performance, financial and social risks. Goyal (2008) mentioned that consumers' perceived risks during the purchase would influence their decisions to purchase. Moreover, consumers will search for more information to reduce their purchase risks when they purchase products with higher value and perceived risk.

Quintal, Lee and Soutar (2008) also documented that perceived risk had a greater impact on attitude towards behaviour. Farrukh (2010) argued that the major reason for a smaller proportion of stockholding is the perception of stocks as an extremely risky investment. Generally, stock investment is perceived to be extremely risky and the possibilities of money loss are high.

Cuong and Jian (2014) revealed that perceived risk negatively affects individual investor's attitude which in 
turn affects their behavioural intention. Thus, it is reasonable to anticipate that when investors perceive high levels of perceived risk, their expectations and satisfied feelings are formed with less stability. Therefore, highly perceived risk may cause investors' unstable feelings.

Bailey and Kinerson (2005) are also of the view that there is a strong relationship between perceived risk (selfassessed) and investment behaviour. Thus perceived risk is a critical factor influencing a consumer's purchase decision (Yee \& San, 2011; Chen \& Chang, 2012).

Chen and Chang (2012) mentioned that perceived risk is powerful at explaining consumer behaviour because consumers are often motivated to reduce risk than to maximise utility in their purchase processes. In this research context it is expected that increasing highrisk perception undermines investing intention, and reduces the likelihood of investors making the investment. Based on the findings from previous research, this current study proposes to test another hypothesis, namely:

H3: Perceived risk will have a significant impact on investment intention of individual investors.

\section{DATA AND METHODOLOGY}

The data was collected from a sample of 548 Pakistani individual investors. The data was collected with the help of a self-administered questionnaire. The questionnaire contains two section in which the first section asks about the demographic information and the second section was on the main constructs, namely, uncertainty avoidance, risk avoidance, perceived risk and investment intentions.

\section{MEASURES}

The measure for Risk Avoidance was adapted from Lim, Soutar and Lee (2013) and Quintal, Lee and Soutar (2006). The scale to measure Uncertainty Avoidance was adapted from the study of Lim (2013). The measurement of perceived risk was adapted from Lim (2013 and Ali and Tariq (2013) while the measure for investment intention was adapted from the study of Lim (2013) and Allen, Gupta and Monnier (2008) as given in Table 1.

\begin{tabular}{lll}
\multicolumn{2}{l}{ Table 1. Measurement Scales } \\
\hline Instruments & Items & Source \\
\hline Risk Avoidance & 08 & $\begin{array}{l}\text { Lim et al. (2013); } \\
\text { Quintal, Lee and } \\
\text { Soutar (2006) }\end{array}$ \\
Uncertainty Avoidance & 05 & Lim (2013) \\
Perceived Risk & 08 & $\begin{array}{l}\text { Lim (2013); Ali and } \\
\text { Tariq (2011) }\end{array}$ \\
Investment Intentions & 07 & $\begin{array}{l}\text { Lim (2013); Allen, } \\
\text { Gupta and Monnier } \\
\text { (2008) }\end{array}$ \\
\hline
\end{tabular}

\section{DATA ANALYSIS}

The descriptive analysis of demographics of the respondents showed that there were $65 \%$ male and $33 \%$ female respondents. Most of the respondents were of the age group 2535 years and have an average income Rs.25000- Rs.50,000. The details of the demographic profile of respondents is given in Table 2.

\begin{tabular}{|c|c|c|c|}
\hline $\begin{array}{l}\text { Demo- } \\
\text { graphic } \\
\text { Factors }\end{array}$ & Components & Frequency & $\begin{array}{l}\text { Percent- } \\
\text { age }\end{array}$ \\
\hline \multirow{4}{*}{ Gender } & Male & 357 & 65.1 \\
\hline & Female & 181 & 33.0 \\
\hline & Missing & 10 & 1.8 \\
\hline & Total & 548 & 100 \\
\hline \multirow{7}{*}{ Age } & $\begin{array}{l}\text { Less than } 25 \\
\text { years }\end{array}$ & 155 & 28.3 \\
\hline & 25-35 years & 284 & 51.8 \\
\hline & 36-45 years & 55 & 10.0 \\
\hline & 46-55 years & 29 & 5.3 \\
\hline & $\begin{array}{l}56 \text { years or } \\
\text { above }\end{array}$ & 13 & 2.4 \\
\hline & Missing & 12 & 2.2 \\
\hline & Total & 548 & 100 \\
\hline
\end{tabular}


Hasanuddin Economics and Business Review

Vol. 3 No. 1 (21-33)

\begin{tabular}{|c|c|c|c|}
\hline \multirow{7}{*}{ Income } & $\begin{array}{l}\text { Below Rs. } \\
25,000\end{array}$ & 117 & 21.4 \\
\hline & $\begin{array}{l}\text { Rs. } 25000- \\
\text { Rs. } 50,000\end{array}$ & 174 & 31.5 \\
\hline & $\begin{array}{l}\text { Rs. } 51000- \\
\text { Rs. } 75,000\end{array}$ & 117 & 21.4 \\
\hline & $\begin{array}{l}\text { Rs. } 76,000- \\
\text { Rs. } 100,000\end{array}$ & 82 & 15.0 \\
\hline & $\begin{array}{l}\text { Rs. 101,00o } \\
\text { and Above }\end{array}$ & 40 & $7 \cdot 3$ \\
\hline & Missing & 18 & $3 \cdot 3$ \\
\hline & Total & 548 & 100 \\
\hline
\end{tabular}

Further analysis of the measurement model such as construct reliability and validity were executed using structural equation modelling (SEM) technique, using partial least squares (PLS) with SmartPLS 3.0. Kashif, Zarkada and Ramayah (2016) mentioned that SmartPLS is a second-generation analysis software that can be used to test complex models with latent variable. In order to assess the measurement model the procedure suggested by Anderson and Gerbing (1988) was followed. In this two-step approach, the first step is adapted to test the measurement model and a second step for the structural model in order to test the hypothesis.

In the measurement model, CFA technique was used to assess the items of the constructs and the items with lower factor loadings were removed. The construct reliability and validity were assessed using the criterion suggested by Fornell and Larcker (1981), in which the construct validity is assumed when the value of the composite reliability is 0.70 or above. The constructs will be assumed to have acceptable construct validity when the value of Average Variance Extracted (AVE) is 0.50 or above. In the current study, both reliability of construct validity and composite reliability were established, and all the constructs fulfilled the criterion given by Fornell and Larcker (1981). The structural model was run using PLS-SEM.

In order to assess the measurement model, the literature suggests considering loading on three indicators, namely average variance extracted (AVE), composite reliability (CR) and convergent validity (CV). $\mathrm{CV}$ ensures whether the items of measurement represent the one and same underlying construct. As per criterion suggested by Chin, Gopal and Salisbury (1997) and Gholami, Sulaiman, Ramayah and Molla (2013), the loadings of the indicators should be above 0.6. The value of AVE should be above 0.5 and CR should be above 0.7. The fulfilment of these criteria assures the fitness of the measurement model. As indicated in Table 3 all the values were above the recommended values and ensured the value of $\mathrm{CV}$ is acceptable.

\begin{tabular}{|c|c|c|c|c|}
\hline Constructs & Items & Loadings & AVE & $\mathrm{CR}$ \\
\hline \multirow{4}{*}{ Risk Avoidance } & RA4 & 0.772 & \multirow{4}{*}{0.538} & \multirow{4}{*}{0.715} \\
\hline & RA6 & 0.711 & & \\
\hline & RA5 & 0.761 & & \\
\hline & RA8 & 0.688 & & \\
\hline \multirow{5}{*}{$\begin{array}{l}\text { Uncertainty } \\
\text { Avoidance }\end{array}$} & UA1 & 0.592 & \multirow{5}{*}{0.553} & \multirow{5}{*}{0.780} \\
\hline & UA2 & 0.728 & & \\
\hline & UA3 & 0.784 & & \\
\hline & UA4 & 0.776 & & \\
\hline & UA5 & 0.753 & & \\
\hline \multirow{5}{*}{ Perceived Risk } & PR1 & 0.720 & \multirow{5}{*}{0.523} & \multirow{5}{*}{0.798} \\
\hline & PR2 & 0.762 & & \\
\hline & $\mathrm{PR}_{3}$ & 0.600 & & \\
\hline & PR6 & 0.621 & & \\
\hline & PR7 & 0.877 & & \\
\hline \multirow{7}{*}{$\begin{array}{l}\text { Investment } \\
\text { Intentions }\end{array}$} & II1 & 0.703 & \multirow{7}{*}{0.672} & \multirow{7}{*}{0.919} \\
\hline & II2 & 0.779 & & \\
\hline & II3 & 0.843 & & \\
\hline & $\mathrm{II}_{4}$ & 0.901 & & \\
\hline & II5 & 0.869 & & \\
\hline & II6 & 0.861 & & \\
\hline & II7 & 0.767 & & \\
\hline
\end{tabular}


In the next step of the analysis, the analysis for the discriminant validity(DV) was done to ensure that the construct in the models differs from each other. The value of square root of AVE was compared with correlation among the constructs. The cases where the value of square root of AVE is greater than correlation value in row and column confirmed that the measures are discriminant. In Table 4, the values of square roots of AVE in the rows and columns were higher than the correlations, showing that constructs are discriminant.

Table 4. Discriminant Validity

\begin{tabular}{|c|c|c|c|c|}
\hline & 1 & 2 & 3 & 4 \\
\hline Risk Avoidance & 0.734 & & & \\
\hline $\begin{array}{l}\text { Uncertainty } \\
\text { Avoidance }\end{array}$ & 0.309 & 0.730 & & \\
\hline Perceived Risk & 0.212 & 0.102 & 0.723 & \\
\hline $\begin{array}{l}\text { Investment } \\
\text { Intentions }\end{array}$ & 0.124 & 0.142 & -0.089 & 0.820 \\
\hline
\end{tabular}

Note: Value on the diagonal (bold) represents the square root of AVE and while off the diagonals are correlations

\section{HYPOTHESES TESTING}

After satisfactory results of the measurement model, hypotheses testing was conducted using a structural model with bootstrapping of 7000. The results of proposed hypotheses testing ( $\mathrm{H} 1$; $\beta=0.202, \quad p<0.01)$ showed that Risk Avoidance has significant influence over investment intentions. The results also showed that Uncertainty Avoidance has a significant influence on investment intentions ( $\mathrm{H} 2 ; \beta=0.103, \mathrm{p}<0.05)$. On the other hand, the current study failed to support the notion that perceived risk have an influence on investment intentions ( $\left.\mathrm{H}_{3} ; \beta=-0.117, \mathrm{p}>0.05\right)$. Based on the results $\mathrm{H} 1, \mathrm{H} 2$ are supported but the results do not support $\mathrm{H}_{3}$ as depicted in Table 5 .

Hair, Ringle, and Sarstedt (2013) recommended that Q2 should be calculated. Q2 can effectively be used as a criterion for predictive relevance (Stone
1974; Geisser 1975; Fornell and Cha 1994; Chin 2010). Based on blindfolding procedure, Q2 evaluates the predictive validity of a large complex model using PLS. While estimating parameters for a model under blindfolding procedure, this technique omits data for a given block of indicators and then predicts the omitted part based on the calculated parameters (Hair et al., 2013). As the Q2 value of 0.039 for investment intention is larger than $\mathrm{o}$ as per criterion given by Fornell and Larcker (1981), the model can be considered to have sufficient predictive power. In PLS the most frequently used model's fitness criteria given are Standardized Root Mean Square Residual (SRMR) and Normed Fit Index (NFI). The value of SRMR for the current model is 0.063 and it is within acceptable range as suggested by $\mathrm{Hu}$ and Bentler (1999). According to $\mathrm{Hu}$ and Bentler (1999), a value less than 0.08 is generally considered as a good fit. Moreover, the value of NFI is 0.812 which is also within acceptable range and indicates the model achieved a good fit.

\begin{tabular}{llllll}
\multicolumn{6}{l}{ Table } \\
\hline $\begin{array}{l}\text { Hy- } \\
\text { poth- } \\
\text { eses }\end{array}$ & $\begin{array}{l}\text { Relation- } \\
\text { ship }\end{array}$ & $\beta$ & t-value & P & Decision \\
\hline H1 & RA => II & 0.202 & 4.746 & 0.000 & Supported \\
H2 & UA => II & 0.103 & 2.127 & 0.033 & Supported \\
H3 & PR => II & 0.117 & 1.387 & 0.166 & $\begin{array}{l}\text { Not } \\
\text { Supported }\end{array}$
\end{tabular}

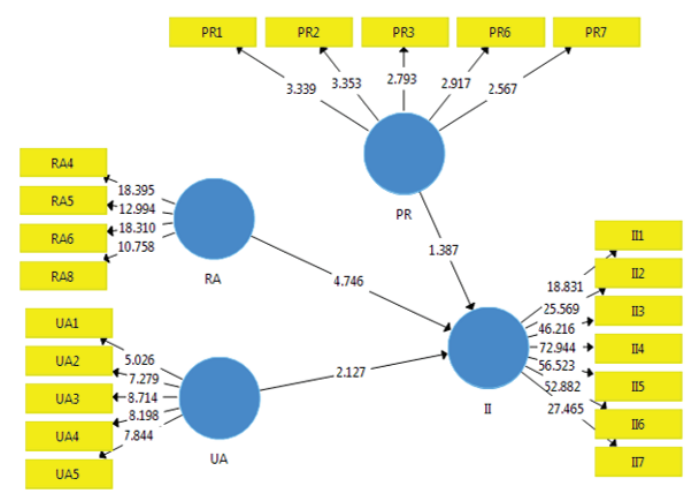

Figure 2. Hypothesis testing results 


\section{DISCUSSION AND CONCLUSION}

In studies about financial investment, a lot of emphasis has been given to the importance of risk and its impact on the decision making of individuals. Behavioural finance views this phenomenon from the perspective of psychological and human factors instead of mathematical calculation (Wang et al. 2011). The current study considered the behavioural perspective of investors to assess the influence of uncertainty avoidance, risk avoidance and perceived risk, taking into account Hofstede's cultural dimension. The findings of the research provide a strong empirical justification for reduced contribution of individual investors in Pakistani Stock Exchange as an outcome of their high level of uncertainty avoidance and risk avoidance during investment in stocks. Uncertainty avoidance is the most significant factor that impacts on the investment intentions of the individual investors. The result of all the three hypothesis tested in this research is in line with the Hofstede (2010) UAI index. The score on UAI is 70 which is very high as compared to other countries in the region. The results are also supported by the findings of Lim (2013) who found that risk avoidance significantly influences the investment intentions of the investors. Amirhosseini and Okere (2012) also reported in their study that uncertainty avoidance exerts a significant impact on investment decisions. Investors tend to avoid situations loaded with uncertainty and in the context of Pakistan, stock investment is considered as uncertain and unpredictable in terms of outcomes. Moreover, the investors in Pakistan, due to their uncertainty avoidance culture, are more cautious about the investment decisions and avoid investment in stock due to the uncertain situation of the stock market.

In the findings, it was revealed that risk avoidance also significantly impact on the investment intentions of individual investors. The findings are supported by studies made by Gambetti and Giusberti (2012) and Bennet et al. (2011) who documented the significant impact of risk avoidance on the investment decision of individuals. Findings by Quintal, et al. (2010) also supported the view that in a situation where individuals perceive to encounter a financial loss, their behaviour towards purchasing the risky product will be affected. In Pakistan, an investment in stock market is considered riskier. Consequently investors tend to avoid investing in the stock market.

Moreover, the findings showed perceived riskhasanon-significantimpact on investment intentions of individual investors. This finding contradicts findings in most of the previous literature. In the context of Pakistan, perceived risk is not a significant predictor of the intentions of the individual investors in Pakistan. This finding seems a unique finding which suggests that the cultural dimension of uncertainty avoidance appears more significant as compared to the individual's own risk perception. The culture of uncertainty avoidance and the tendency of risk avoidance by investors is a strong factor. The findings can be linked to the collective culture of Pakistan. As per Hofstede (2001), Pakistan, with low score of 14 on individualism index, is considered a collectivistic society. In collectivistic society decision making might not be effected by individual's perception of risk but by collective opinion that views stock investment is a risk investment option. Thus, this study concludes that uncertainty avoidance and risk avoidance of investors are major factors that can significantly influence the decision making of individual investors.

\section{MANAGERIAL IMPLICATIONS}

The findings of the study have several 
implications for individual investors, stock brokers and the Security Exchange Commission of Pakistan. It was found that uncertainty avoidance index of Pakistan is too high as compared to other neighbouring countries and this uncertainty avoidance emerged as a strongfactorthatinfluences theintentions of individual investors. Individual who possesses significant information regarding the financial consequences of the products purchased would most definitely make a different decision (Kahneman, 2011). This signifies that the amount of information is one of the factors influencing decision making. As a result, individuals who are uncertain of the situation are more reluctant to make investment decisions. Thus awareness about stock investment and knowledge of stock market products can be helpful to reduce the uncertainty among investors. Moreover, risk avoidance was found to significantly influence the investment intentions of individual investors. In a situation where investors have high-risk perception and estimate the financial loss in investment decisions, they usually tend to develop strategies to reduce their risk (i.e. sourcing information) and make more risk-adjusted decisions. In the case of Pakistani investors, stock brokers and Security Exchange Commission should provide quality information to the investors to make their financial decisions easy. It is recommended that the financial products in the stock market should comprise of a variety of risk-levels based on the investor's risk appetite. The risk lovers can be offered high risk products and the risk averse should be offered some risk adjusted products to reduce the level of risk avoidance among the investors. This can help increase the level of investments in the stock market and to induce more individual investors to invest in the stock market. Findings of the current study are expected to be useful in realising the importance of uncertainty avoidance and risk avoidance culture of individual investors in attracting the individual investors to invest in stock market.

\section{Limitations and future research directions}

The current study only focuses on three aspects which are uncertainty avoidance, risk avoidance and perceived risk on investment intentions of individual investors. Future studies may cover other relevant aspects and can use all dimensions of culture given by Hofstede to assess the impact of the other dimensions on stock investment. The study also collected cross sectional data from employed investors, future research may include business owners and other investors to get more variety of respondents. It might be useful to assess the investment intentions of individual investors over the time by employing a longitudinal setting.

\section{REFERENCES}

Ali, I., \& Tariq, A. (2013). Factors Affecting Individual Equity Investor's Decision Making in Pakistan. Journal of International Education in Business,1(1) 18-31.

Allen, M. W., Gupta, R., \& Monnier, A. (2008). The interactive effect of cultural symbols and human values on taste evaluation. Journal of Consumer Research, 35(2), 294308.

Amirhosseini, Z., \& Okere, V. O. (2012). Effect of Cultural Dimensions on Stock Exchange Investment Decisions in Iran. Journal of Business \& Economics Research, 10(12), 681- 688.

Anderson, J. C., \& Gerbing, D. W. (1988). Structural equation modeling in practice: A review and recommended two-step approach. Psychological Bulletin, 103(3), 411- 
423.

Aqueveque, C. (2006). Extrinsic cues and perceived risk: the influence of consumption situation. Journal of Consumer Marketing, 23(5), 237247.

Bailey, J. J., \& Kinerson, C. (2005). Regret avoidance and risk tolerance. Financial Counseling and Planning, 16(1), 23-28.

Bennet, E., Selvam, M., Indhumathi, G., Ramkumar, R. R., \& Karpagam, V. (2011). Factors Influencing Retail Investors Attitude towards Investing In Equity Stocks: A Study in Tamil Nadu. Journal of Modern Accounting and Auditing, 7(3), 316321.

Bommier, A., \& Le Grand, F. (2014). Too Risk Averse to Purchase Insurance? A Theoretical Glance at the Annuity Puzzle. Journal of Risk and Uncertainty, 48(1), 135-166.

Bommier, A., Chassagnon, A., \& Le Grand, F. (2012). Comparative risk aversion: A formal approach with applications to saving behavior. Journal of Economic Theory, 147(4), 1614-1641.

Brewer, N. T., Chapman, G. B., Gibbons, F. X., Gerrard, M., McCaul, K. D., \& Weinstein, N. D. (2007). Metaanalysis of the relationship between risk perception and health

behavior: The example of vaccination. Health Psychology, 26(2), 136 - 145 .

Carvalho, S. W., Block, L. G., Sivaramakrishnan, S., Manchanda, R. V., \& Mitakakis, C. (2008). Risk perception and risk avoidance: The role of cultural identity and personal relevance. International Journal of Research in Marketing, 25(4), 319-326.

Chen, Y. S., \& Chang, C. H. (2012). Enhance green purchase intentions: The roles of green perceived value, green perceived risk, and green trust. Management Decision, 50(3), 502-520.

Chin, W. W., Gopal, A., \& Salisbury, W. D. (1997). Advancing the theory of adaptive structuration: The development of a scale to measure faithfulness of appropriation. Information Systems Research, 8(4), 342-367.

Cuong, P. K., \& Jian, Z. (2014). Factors Influencing Individual Investors' Behavior: An Empirical Study of the Vietnamese Stock Market. American Journal of Business and Management, 3(2), 77-94.

Dai, B., Forsythe, S., \& Kwon, W. S. (2014). The impact of online shopping experience on risk perceptions and online purchase intentions: does product category matter?. Journal of Electronic Commerce Research, 15(1), 13-24.

De Mooij, M., \& Hofstede, G. (2011). Cross-cultural consumer behavior: A review of research findings. Journal of International Consumer Marketing, 23(3-4), 181-192.

Dowling, G. R., \& Staelin, R. (1994). A model of perceived risk and intended risk-handling activity. Journal of Consumer Research, 21(1), 119-134.

Drakos, K. (2006). A note on uncertainty and investment across the spectrum of irreversibility. Applied Economics Letters, 13(13), 873876.

Eisingerich, A. B., \& Rubera, G. (2010). Drivers of brand commitment: A crossnational investigation. Journal of International Marketing, 18(2), 64-79.

Enron (2010). Risk management. The Review of Economic Studies. 20 (2), 15-22.

Farrukh.K. (2010). Investment outlook: The case for equities. Next Capital Research, 1-6. 
Felton, J., Gibson, B., \& Sanbonmatsu, D. M. (2003). Preference for risk in investing as a function of trait optimism and gender. The Journal of Behavioral Finance, 4(1), 33-40.

Ferecatu, A., \& Önçüler, A. (2016). Heterogeneous risk and time preferences. Journal of Risk and Uncertainty, 53(1), 1-28.

Fornell, C., \& Larcker, D. F. (1981). Evaluating structural equation models with unobservable variables and measurement error. Journal of Marketing Research, 39-50.

Franklin, S. C., \& Corter, J. E. (2010). Risk aversion and uncertainty aversion as distinct traits. unpublished paper, Teachers College, Columbia University.

Gambetti, E., \& Giusberti, F. (2012). The effect of anger and anxiety traits on investment decisions. Journal of Economic Psychology, 33(6), 10591069.

Gholami, R., Sulaiman, A. B., Ramayah, T., \& Molla, A. (2013). Senior managers' perception on green information systems (IS) adoption and environmental performance: Results from a field survey. Information \& Management, 50(7), 431-438.

González Mieres, C., María Díaz Martín, A., \& Trespalacios Gutiérrez, J. A. (2006). Antecedents of the difference in perceived risk between store brands and national brands. European Journal of Marketing, 40(1/2), 61-82.

Goyal, A. (2008). Managing perceived risk for credit card purchase through supplementary services. Journal of Financial Services Marketing, 12(4), 331-345.

Hair, J. F., Ringle, C. M., \& Sarstedt, M. (2013). Editorial-partial least squares structural equation modeling: Rigorous applications, better results and higher acceptance. Long Range Planning, 46(1-2), 1-12.

Hallahan, T. A., Faff, R. W., \& McKenzie, M. D. (2004). An empirical investigation of personal financial risk tolerance. Financial Services Review, 13(1), 57-78.

Hofstede, G. H., \& Hofstede, G. (2001). Culture's consequences: Comparing values, behaviors, institutions and organizations across nations. Sage.

Hofstede, G. H., Hofstede, G. J., \& Minkov, M. (2010). Cultures and organizations: software of the mind intercultural cooperation and its importance for survival. New York: McGraw-Hill.

Howcroft, B., Hewer, P., \& Hamilton, R. (2003). Consumer decision making styles and the purchase of financial services. Service Industries Journal, 23(3), 63-81.

Hu, L. t., \& Bentler, P. M. (1999). Cutoff criteria for fit indexes in covariance structure analysis:

Conventional criteria versus new alternatives. Structural Equation Modeling: A

Multidisciplinary Journal, 6(1), 1-55.

Iyke, B. N., \& Ho, S. Y. (2017). Exchange rate uncertainty and domestic investment in Ghana. Cogent Economics \& Finance, 5(1), 1-12.

Kahneman, D., \& Tversky, A. (1979). Prospect theory: An analysis of decision under risk. Econometrica: Journal of the Econometric Society, 263-291.

Kashif, M., Zarkada, A., \& Ramayah, T. (2016). The impact of attitude, subjective norms, and perceived behavioural control on managers' intentions to behave ethically. Total Quality Management \& Business Excellence, 1-21.

Knoll, M. A. (2010). Role of Behavioral Economics and Behavioral Decision 
Making in Americans' Retirement Savings Decisions, The. Soc. Sec. Bull., 70 (4).

Lim, K. L. (2013). Investment Intentions: A Consumer Behaviour Framework (Doctoral dissertation, University of Western Australia).

Lim, K. L., Soutar, G. N., \& Lee, J. A. (2013). Factors affecting investment intentions: A consumer behaviour perspective. Journal of Financial Services Marketing, 18(4), 301-315.

MacGregor, D. G., P. Slovic, M. Berry, and H. R. Evensky (1999). Perception of

Financial Risk: A Survey Study of Advisors and Planners. Journal of Financial Planning, 12 (8), 68-86.

Mayfield, C., Perdue, G., \& Wooten, K. (2008). Investment management and personality type. Financial Services Review, 17(3), 219-236.

Morse, W. C. (1998). Risk taking in personal investments. Journal of Business and Psychology, 13(2), 281-288.

O'Barr, W. M., \& Conley, J. M. (2000). When Cultures Collide: Social Security and the Market. The Journal of Psychology and Financial Markets, 1(1), 92-100.

Olsen, R. A., \& Cox, C. M. (2001). The influenceofgenderontheperception and response to investment risk: The case of professional investors. The Journal of Psychology and Financial Markets, 2(1), 29-36.

Pennings, M. E., Wansink, B., \& Meulenberg, M. T. G. (2002). A note on modeling

consumer reactions to a crisis: The case of the mad-cow disease. International Journal of Research in Marketing, 19 (1), 91-100.

Quintal, V. A., Lee, J. A., \& Soutar, G. N. (2010). Risk, uncertainty and the theory of planned behavior: A tourism example. Tourism Management, 31(6), 797-805.
Quintal, V., Lee, J., \& Soutar, G. (2006). Attitudes towards risk and uncertainty: suggested scales. Proceedings of the Australian and New Zealand Marketing Academy, 4.

Rizvi, A., \& Ali, S. B. (2011). Risk Taking Behavior of Investors of Pakistan (No. 64342). University Library of Munich, Germany.

Sevdalis, N., \& Harvey, N. (2007). "Investing" versus "Investing for a Reason": Context Effects in Investment Decisions. The Journal of Behavioral Finance, 8(3), 172176.

Siau, K., \& Shen, Z. (2003). Building customer trust in mobile commerce. Communications of the ACM, 46(4), 91-94.

Wang, M., Keller, C., \& Siegrist, M. (2011). The less you know, the more you are afraid of-A survey on risk perceptions of investment products. Journal of Behavioral Finance, 12(1), 9-19.

Weber, E. U., \& Bottom, W. P. (1989). Axiomatic measures of perceived risk: Some tests and extensions. Journal of Behavioral Decision Making, 2(2), 113-131.

Yee, C. J., \& San, N. C. (2011). Consumers' perceived quality, perceived value and perceived risk towards purchase decision on automobile. American Journal of Economics and Business Administration, 3(1), 47-57. 